ISSN 1981-416X

Licenciado sob uma Licença Creative Commons

\title{
Educação online mediada pelo WhatsApp: mapeando rastros e controvérsias de alunos à luz da teoria ator-rede
}

\author{
Online education through WhatsApp: mapping traces and \\ controversies of students in the light of the theory actor-web
}

Educación en línea mediada por WhatsApp: mapeando rastros y controversias de alumnos la luz de la teoría actor-red

André Luiz Alves, Cristiane de Magalhães Porto, Kaio Eduardo de Jesus Oliveira*

Universidade Tiradentes, Aracaju, SE, Brasil

\section{Resumo}

Este artigo analisa a contribuição e os usos do aplicativo WhatsApp no processo de aprendizagem colaborativa. Para isso, a experiência descrita neste trabalho foi articulada por meio da associação de um desenho didático, conectado a práticas pedagógicas e educativas, que favorecem a aprendizagem ubíqua por meio de experiências de app-learning,

ALA: Doutorando em Educação, e-mail: anndrealves@hotmail.com

CMP: Doutora Multidisciplinar em Cultura e Sociedade, e-mail: crismporto@gmail.com

KEJO: Doutorando em Educação, e-mail: kaioeduardojo@gmail.com 
que se materializa espaço-temporalmente no uso do WhatsApp. Deste modo, parte-se da perspectiva epistemológica da Teoria Ator-Rede na análise de controvérsias articulada à rede educativa formada. Com isso, defende-se aqui o argumento de que a associação dos sujeitos aos objetos em suas mediações, traduções e agenciamentos favorecem o processo de ensino-aprendizagem e o desenvolvimento de uma prática pedagógica mais articulada entre os envolvidos - seja entidade humana ou não-humana e integrada às práticas culturais da Cibercultura. Como método, utiliza-se o estudo de caso qualitativo e de cunho descritivo. Os resultados obtidos possibilitam concluir que o engajamento dos sujeitos quanto ao uso do WhatsApp, articulado ao desenho didático e à proposta pedagógica, configura uma experiência de app-learning, principalmente pelo estabelecimento dos processos de mediação do ensino e da aprendizagem.

Palavras-chave: App-learning. Educação. Cultura Digital.

\begin{abstract}
This article analyses the contribution and uses of the Whatsapp application in the process of collaborative learning. For this, the app-learning experience described in this article was articulated through the association of a didactic drawing connected to pedagogical and educative practices that favors ubiquitous learning combined to app-learning experiences that materializes space-time in the use of WhatsApp. That way, coming from the epistemological perspective of the Actor-Web theory on the analysis of controversies, the argument here defended is that the subject's association to the objects of its mediations, translations and scheduling favors the teaching-learning process and the development of a pedagogical practice, one that is more articulated between the involved - human or not and integrated to the cultural practices of the Cyberculture. As method, the study of the qualitative case and of descriptive matter are used. The obtained results make it possible to conclude that the subjects' engagement regarding the use of Whatsapp, articulated to the didactic drawing and the pedagogical proposal, configures an app-learning experience, mainly by the establishment of mediation processes of teaching and learning.
\end{abstract}

Keywords: App-learning. Education. Cyberculture. 


\section{Resumen}

Este artículo analiza la contribución y los usos del aplicativo WhatsApp en el proceso de aprendizaje colaborativa. Para eso, la experiencia descrita en este trabajo ha sido articulada por medio de la asociación de un diseño didáctico especifico y conectado prácticas pedagógicas y educativas que favorecen el aprendizaje ubicua combina a las experiencias de app-learning, que se materializa espacio-temporalmente, en el uso del Whatsapp. De este modo, partiendo de la perspectiva epistemológica de la Teoría Actor-Red en el análisis de controversias, se defiende aquí el argumento de que la asociación de los sujetos a los objetos en sus mediaciones, traducciones y gestión; favorecen el proceso de enseñanza-aprendizaje y el desarrollo de una práctica pedagógica más articulada entre nos envueltos - sea entidad humana o no-humana e integrada a las prácticas culturales de la Cibercultura. Como método, se utiliza el estudio de caso cualitativo y de carácter descriptivo. Los resultados obtenidos posibilitan concluir que el comprometimiento de los sujetos cuanto al uso del WhatsApp, articulado al diseño didáctico y a la propuesta pedagógica, configura una experiencia de app-learning, principalmente, por el establecimiento de los procesos de medicación de enseñanza y del aprendizaje.

Palabras clave: App-learning. Educación. Cultura Digital.

\section{Proposição}

Fomentar o uso das tecnologias digitais em processos educativos pode possibilitar que os sujeitos envolvidos se reconheçam, cada vez mais, protagonistas do seu processo de aprendizagem e, assim, estabeleçam conexões mais significativas com a produção do conhecimento. Deste modo, analisar as associações que estudantes realizam na Cibercultura e com os dispositivos disponíveis em suas práticas sociais e culturais que favorecem, também, sua relação com a aprendizagem, se configura como uma pertinente controvérsia para compreensão da relação entre cultura, dispositivos e educação. Visto que, os dispositivos digitais e as 
práticas culturais da Cibercultura, nem sempre estão articulados a objetivos pedagógicos.

Com a liberação do polo de emissão, a educação online caracteriza-se por uma educação todos-todos, onde a interatividade se coloca como grande diferencial no que diz respeito à comunicação que se estabelece entre alunos e professor. Outra peculiaridade da educação online é a sua capacidade de hibridizar e permutar, num mesmo ambiente várias mídias; a partir das aprendizagens construídas e dinamizadas pela apropriação de artefatos culturais, tecnologias, interações sociais, entre outros. Logo, entendemos que a educação online, que defendemos neste artigo não é uma evolução das práticas da Educação a Distância (EAD), e sim, um fenômeno da Cibercultura (SANTOS, 2014).

Neste sentido, nos propomos aqui a problematizar a configuração de uma experiência de educação online modelada a partir da bricolagem de práticas educativas. Esta experiência bricolada se caracteriza pela associação de um desenho didático que promove aprendizagem ubíqua a partir de dispositivos que favorecem a aprendizagem. Como ambiente central de mediação, tomamos o WhatsApp Messenger como espaço-tempo de associação entre actantes. O que nos remete ao conceito da Teoria Ator-Rede, por evidenciar os agentes que desempenham função de agenciamento e engajamento em uma rede sociotécnica, seja ele humano ou não-humano, sujeito ou objeto. Assim, compondo um cenário propício para a formação de uma controvérsia na formação da rede educativa.

Entendemos aqui, controvérsias como pontos de formação das articulações e associações, elas são o lugar onde se estabelecem as contradições e, a partir delas, as associações. Lemos (2013, p. 106) enfatiza que "a TAR tem nas controvérsias o momento e o lugar privilegiado para observar a circulação, a criação e o término das associações, para observar a agregação social". Dessa forma, problematizar a imbricada relação entre ensino-aprendizagem e práticas sociais contemporâneas fez-se pertinente para este contexto. 
À vista disso, o uso do WhatsApp na experiência aqui descrita, não figura apenas função intermediária da ação, um objeto em causa, mas um dispositivo que produz causa e efeito na rede. Ele é o espaço onde os sujeitos se encontram e se tencionam com um objetivo comum: a aprendizagem. Isto posto, o dispositivo também desempenha função de protagonismo; em vez de aglomerar a rede, ele se torna a própria rede sociotécnica, ou um ator-rede que permite a aprendizagem ubíqua por intermédio de uma experiência de app-learning. Com isso, o conceito de controvérsia ganha mais sentido neste texto, já que um dispositivo - aplicativo digital - passa a desempenhar função principal na rede.

Com isso, conceito de rede se torna fundamental, uma vez que a noção de rede aqui discutida, remete ao fluxo das associações, ao espaço-tempo onde às ações se estabelecem. Segundo Latour (1999, p. 27), "a rede de actantes é sempre aberta, heterogênea de modo que, a princípio, é possível estabelecer todo e qualquer tipo de conexão". Assim, o social passa a ser visto pela formação de associações e formação de redes, as redes sociotécnicas. Estas, pautadas em um objetivo e uma intencionalidade, como é o caso da experiência formativa em estudo. A associação entre smartphones, desenho didático, professores, alunos, espaços físicos e virtuais de aprendizagens compuseram a rede que nomeamos de "WhatsAula", que agrega actantes, implicados pelo ensino, aprendizagem e formação.

Passamos, portanto, a evidenciar a formação desta rede, como rede educativa, um espaço multirreferencial de aprendizagem, espaço plural, no qual seres humanos, objetos técnicos reinventam seus cotidianos. Uma vez que a construção do conhecimento é tecida em rede, a partir da apropriação de diversos artefatos culturais, interações sociais entre outras (SANTOS, 2014).

Logo, este artigo analisa a contribuição e os usos do aplicativo WhatsApp no processo de aprendizagem colaborativa. Como método, utilizamos um estudo de caso qualitativo de cunho descritivo. Os resultados obtidos possibilitam concluir que o engajamento dos sujeitos quanto ao uso do WhatsApp, articulado ao desenho didático e à proposta 
pedagógica, configura uma experiência de app-learning que, não se centra apenas no sujeito, mas nas associações articuladas com dispositivos. Principalmente, pelo estabelecimento da mediação dos processos de ensino e de aprendizagem que foram construídos pelos na rede sociotécnica e pelas associações implicadas no transcorrer da "WhatsAula".

\section{"Whatsaula": do app-learning à aprendizagem ubíqua}

Na Cibercultura, a posição central do Professor no ato de ensinar começou a ser questionada com intensidade a partir do momento em que o Ciberespaço acelerou a velocidade com que as informações e os conteúdos passaram a circular pelo digital em rede - livremente e de maneira descentralizada - ocasionando, consequentemente, produções de outras educações, inclusive a educação online. A educação online, situada no contexto da cibercultura, tem como fundamentos o hipertexto e a interatividade e impõe uma nova reconfiguração social, cultural, econômica e política, ao colocar em xeque o esquema clássico da informação com o polo de emissão liberado, abrindo espaço para o diálogo e a participação colaborativa (SANTOS, 2014).

Dessa forma, neste trabalho, problematizamos a bricolagem de práticas educativas no contexto da Cibercultura, que possibilita novas formas de aprendizagem para configurar um ambiente de ensino, onde o Professor, em vez de exibir conteúdos, pode propor oportunidades de aprendizagem e estabelecer conexões com os alunos e com os dispositivos - de forma mais participativa e engajada.

Propomos assim um processo educativo implicado em um modelo onde os alunos também são produtores ativos de informação e conteúdo, dentro-fora da sala de aula — em rede-grupo-movimento - e o professor um mediador ou facilitador do processo educativo, e os dispositivos digitais disponíveis não efetuam apenas função de coisas, mas se tornam causa e produzem efeito na rede. Essa rede sociotécnica favorece a possibilidade de aprendizagem ubíqua. Santaella (2013), denominou de 
"aprendizagem ubíqua" as novas formas de aprendizagem mediadas pelos dispositivos móveis.

Quando nos referimos à m-learning, ainda estamos no domínio da educação formal e da não-formal porque se trata do desenvolvimento de métodos e recursos que têm como alvo o processo de aprendizagem incorporado a uma sistemática pré-determinada. A m-learning é vista como uma extensão da sala de aula e é executável a partir de um sistema de ensino-aprendizagem previamente estabelecido. É óbvio que a m-learning recorre à comunicação ubíqua, mas a aprendizagem, que se desenvolve graças aos seus procedimentos, está relativamente prevista e incorporada às expectativas do planejamento educacional. Já a aprendizagem ubíqua, espontânea, contingente, caótica e fragmentária é totalmente informal (SANTAELLA, 2013, p. 303).

Nessa lógica, intitulamos nossa experiência de "WhatsAula", devido a sua imersão dentro-fora da Universidade associados a experiências de app-learning (SANTAELLA, 2016) - aprendizagem por meio de aplicativos - apoiada por dispositivos móveis e aplicativo WhatsApp. Uma vez que, se utilizássemos a denominação de "WhatsAVA", estaríamos associando a modalidade E-Learning. Por outro lado, se cunhássemos de "WhatsSala", restringiríamos nossas práticas pedagógicas apenas ao espaço da sala de aula.

A "WhatsAula", possibilita que os alunos construam seus conhecimentos de forma colaborativa, em rede-grupo-movimento; a partir da interação com os pares por meio da intencionalidade pedagógica da aprendizagem ubíqua com a experiência de app-learning. Assim sendo, a experiência de app-learning aqui projetada, não está restrita ao uso de dispositivos digitais móveis de modo aleatório, mas com o objetivo de promover a aprendizagem articulada a um desenho didático e curricular associada a eles. A experiência de app-learning é mediada por aplicativos e sites de redes sociais digitais que potencializam esse processo. Com isso, os alunos podem interagir compartilhar e produzir informações e conteúdos de forma colaborativa, ultrapassando as barreiras espaço-temporal de relações e associações com outros agentes. 
Figura 1 - Arquitetura e desenvolvimento de conceitos em tempos de App-Learning e aluno imerso na rede mediante processo ativo de ensino-aprendizagem

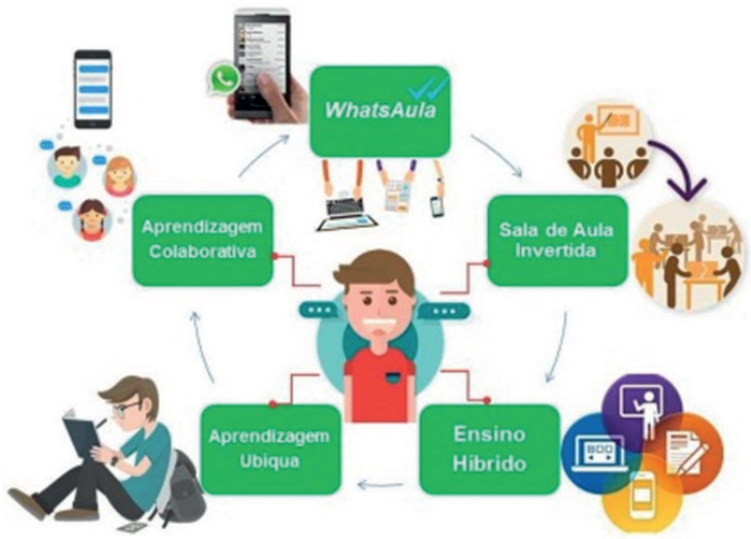

Fonte: Desenho Didático desenvolvido pelos autores em 2017.

A partir deste desenho didático, engajamos os alunos para trabalhar em grupos fixos até o término do semestre, associados a aplicativos, principalmente o WhatsApp, e outras ambiências formativas em rede (Blog) que potencializassem a interação entre pares e a participação ativa na construção do conhecimento. Isso tudo de uma maneira mais autônoma; além de estimular debates, reflexões e exercícios práticos na rotina acadêmica e fluxos interacionais.

Em vista disso, para a configuração de uma experiência de ensino onde o smartphone se estabeleceu como principal mediador da aprendizagem, introduzimos o aplicativo WhatsApp no suporte das práticas de ensino do componente curricular Produção Textual III. Junto com ele, combinamos outras mídias, mesclando o ensino presencial com o online, criamos o conceito de "WhatsAula" e geramos fluxos comunicacionais e interacionais em uma rede sociotécnica extramuros da Universidade que se articulou como principal controvérsia para este trabalho.

Esta controvérsia central foi o que planejamos para ampliar as discussões e o espaço da sala de aula a experiência de educação online. Como também, para impulsionar nossas práticas pedagógicas, e 
potencializar o processo de aprendizagem, por meio dos usos e apropriações do mensageiro instantâneo, conforme elucidaremos a seguir.

\section{Smartphone no modo "aprendizagem"}

A "WhatsAula" figura-se como uma experiência de educação online, permeada pelo uso intencional e pedagógico de dispositivos móveis, mais especificadamente o smartphone. Bem como situada ao contexto de app-learning por meio dos usos do WhatsApp como aplicativo de suporte para o processo de aprendizagem colaborativa em práticas de ensino do componente curricular Produção Textual III (PT-III). Para tanto, no primeiro dia de aula do semestre 2016.2 (agosto a dezembro), discutimos sobre o desenho didático do componente curricular PT-III junto aos alunos do Curso de Comunicação Social: Jornalismo da Unit, matriculados no terceiro período, com definição clara da dinâmica a ser desenvolvida e da sistemática de avaliação.

A turma composta por 21 alunos foi dividida em quatro grupos. Cada grupo demarcou os temas centrais a serem pautados no transcorrer do semestre por meio de assuntos específicos, a saber: Cultura Pop, Meu Busão, Sete Artes e Violência à Grupos Vulneráveis [sic]. Após esta seleção temática, motivada por critérios dos alunos, determinamos que estes (em grupo) tinham, como incumbência produzir textos argumentativos opinativos, crônicas, resenhas - a cada semana e ao longo do semestre - pautando um assunto referente ao seu eixo temático. Feito isto, definimos a mídia social Blog ${ }^{1}$ como um recurso tecnológico complementar das atividades de produção de textos colaborativos.

A escolha da mídia social blog se deu porque ela permite atualização rápida e constante de postagens sobre um assunto em particular;

1 Confira o endereço dos Blogs Temáticos de co-autoria dos pesquisados: Cultura Pop (http://minutos15. blogspot.com.br/), Meu Busão (http://meubusao.weebly.com/), Sete Artes (https://seteartes.wordpress. com/) e Violência à Grupos Vulneráveis [sic] (http://vulneraveisbrasil.blogspot.com.br/). 
além de combinar textos, imagens, vídeos e links para outras páginas da Web relacionadas ao tema. No caso do ensino de Jornalismo, os Blogs têm servido, também, como repositório de exercícios.

A utilização de blogs na educação possibilita o enriquecimento das aulas e projetos através da publicação e interação de ideias na Internet. Basta adequá-los aos objetivos educacionais, para que o conhecimento seja construído através da interação dos recursos informáticos e das capacidades individuais, criando um ambiente favorável para a aprendizagem (VIEIRA; HALU, 2008, online).

Portanto, por intermédio da "WhatsAula", o protagonismo dos alunos é defendido e colocado em prática. Uma vez que, com a liberação do polo de emissão, é possível se apropriar do Blog como mais um espaço de autoria em rede para produzir e circular informações livremente apoiadas na mediação docente - contribuindo com a construção colaborativa de conteúdos e saberes.

Figura 2 - Screenshot dos Blogs Temáticos elaborados pelos alunos
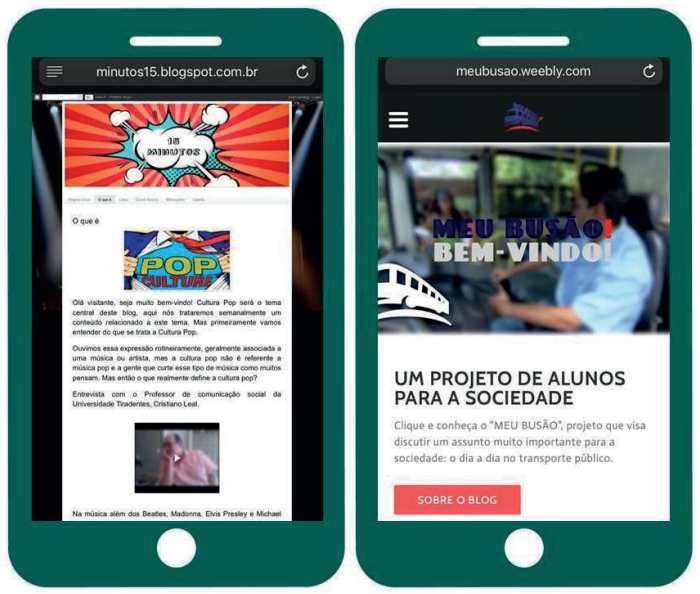


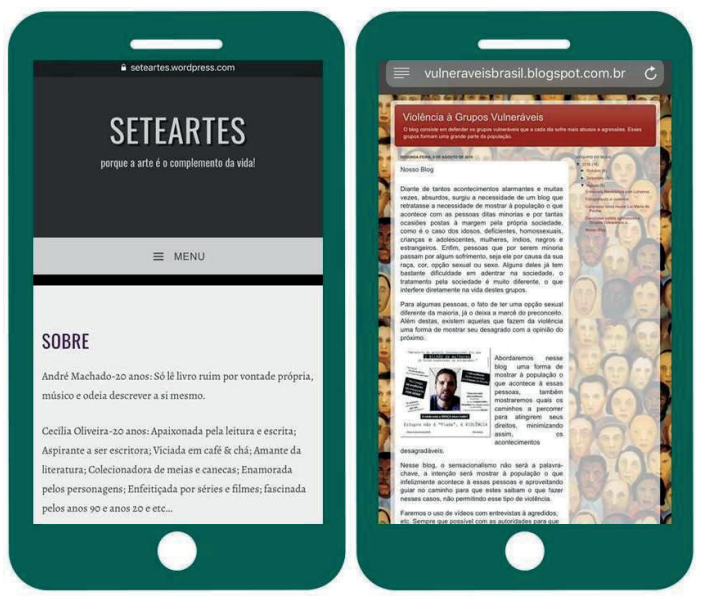

Fonte: Screenshot dos Blogs Temáticos elaborados pelos alunos, André Alves, 2018.

Conforme evidenciam as capturas de tela anteriores, os estudantes de jornalismo criaram os Blogs Temáticos para gerar múltiplos conteúdos relacionados ao eixo temático do trabalho, exercitar sua potência argumentativa opinativa e estilos de escrita em narrativas jornalísticas. O que promoveu um ambiente de discussão que amplia a sala de aula, ao passo que a coautoria e o conhecimento ganham visibilidade e são compartilhados em forma de posts.

A cada semana, todas as noites de segunda-feira os grupos apresentavam em sala de aula produções textuais de coautoria, as quais contemplaram os diversos gêneros textuais estabelecidos no currículo, além de estimulados a inserir mídias alternativas como esquetes teatrais, paródias, charges, poemas e crônicas. No decorrer das apresentações, além da projeção do texto postado no Blog Temático por intermédio do projetor multimídia, os integrantes do grupo, utilizavam notebook e smartphone como dispositivos de leitura e acesso ao conteúdo-informação. Os dispositivos digitais (e analógicos) ali disponíveis, integrados, entraram em cena, mediando a apresentação. 
Figura 3 -Screenshot de Alunos e Professor tecendo conhecimento em rede
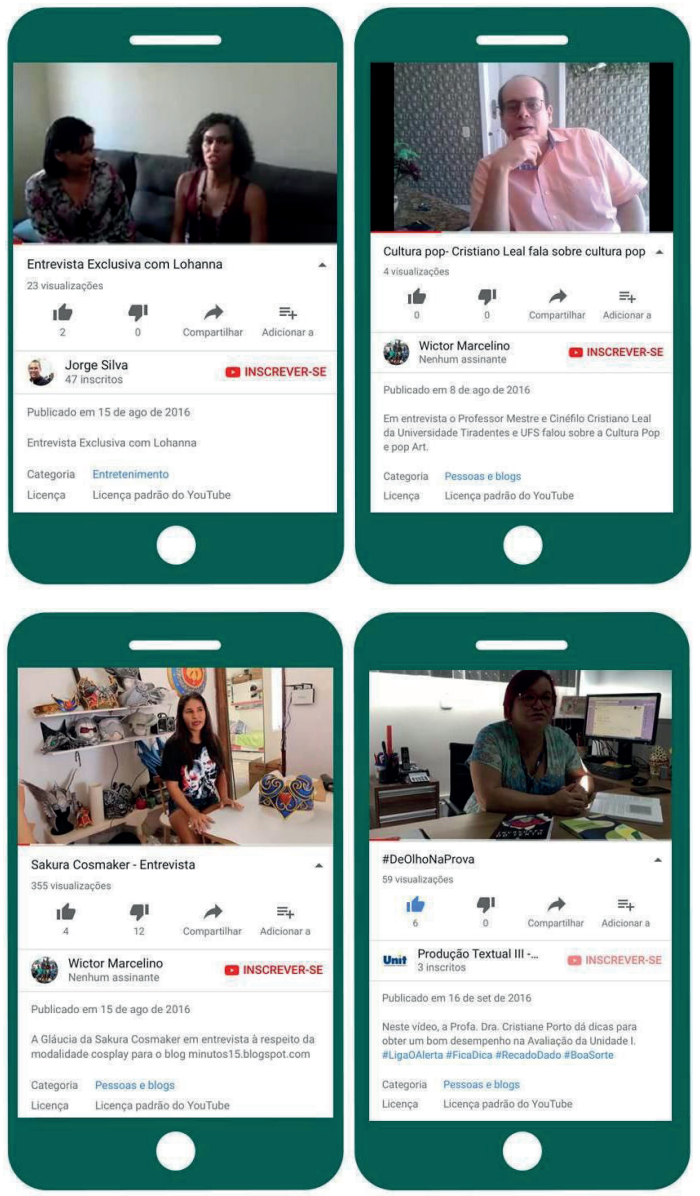

Fonte: André Alves, Screenshot de Alunos e Professor tecendo conhecimento em rede, 2018.

No transcorrer das apresentações, os alunos também bricolaram inúmeros vídeos de autoria para o enriquecimento de suas produções textuais, além de utilizar o YouTube como repositório e "linkar" junto as postagens do Blog Temático. Na primeira captura de tela, a aluna @AnaPaula, integrante do Blog Violência à Grupos Vulneráveis [sic] entrevistou a Transexual sergipana 
Adriana Lohanna dos Santos acerca da homofobia, cujo vídeo foi postado no canal do aluno @Jorge. Na segunda e na terceira capturas de tela, os membros do grupo Cultura Pop entrevistaram o Professor Cristiano Leal, dos Cursos de Jornalismo e Publicidade da Unit e, também, Gláucia da Sakura Cosmaker, sobre o universo da Cultura Pop e os participantes e adeptos da modalidade Cosplay, respectivamente. Já a Professora de PT-III, Cristiane Porto, costumava gravar vídeos no YouTube para compartilhar na "WhatsAula" com dicas e conteúdos do componente curricular.

Em alguns momentos, durante a discussão geral em sala de aula, percebemos que a maioria dos alunos demonstrava interesse ao debate, porém, outros, permaneciam apáticos, sem o mínimo interesse na aula, sendo a única participação ativa a utilização do smartphone ou a conversa paralela com os colegas. Desta forma, o aplicativo WhatsApp funcionou como um aparato tecnológico estruturante das atividades propostas no componente curricular PT-III, o que pode contribuir para as estratégias pedagógicas adotadas serem transformadoras e participativas. Por meio do grupo da turma no aplicativo WhatsApp, nomeado "Produção Textual III", a cada sequência de apresentações todos os alunos prestavam bastante atenção, selecionavam um determinado assunto explanado por cada Blog Temático e comentavam seu olhar crítico (individualmente) na "WhatsAula" por intermédio de mensagens de texto, fotolegenda das apresentações e gravações de vídeo e áudio (Figura 4).

Figura 4 - Screenshot dos fluxos interacionais da "WhatsAula"

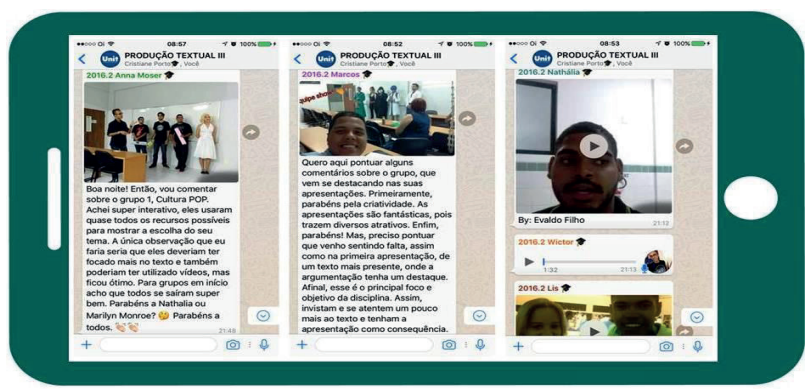

Fonte: André Alves, Screenshot dos fluxos interacionais da "WhatsAula”, 2018. 
Os screenshots de tela anteriores evidenciam as formas plurais de interação, de compartilhamento e de apropriação das funcionalidades do aplicativo por parte dos alunos. A aluna @AnnaMoser, da equipe Violência à Grupos Vulneráveis [sic] disparou uma fotolegenda, elogiando a performance do Blog Cultura Pop, em que seus integrantes produziram uma releitura da foto dos Beatles para o álbum Abbey Road. Além do mais, utilizaram cartazes, vídeos e, mediante esquete teatral, a aluna @Nathália interpretou a atriz, modelo norte-americana e estrela de cinema de Hollywood, Marilyn Monroe (Figura 5). O aluno @Marcos se mostrou em frente às câmeras, para enaltecer as qualidades do grupo em cena e registrar sua crítica quanto ao texto produzido por meio de uma selfie-legenda.

Já o aluno @Evaldo teceu sua argumentação por intermédio de um vídeo gravado com o smartphone. O aluno @Wictor registra seu comentário por meio de áudio, enquanto @Lis dupla com @Saullo, na gravação de um vídeo. Portanto, os alunos propagam suas autorias, cocriando o currículo, por intermédio dos usos e apropriações do WhatsApp, dentro e fora da sala de aula e dos múltiplos espaços multirreferenciais de aprendizagem.

Figura 5 - Alunos exploram outros espaços multirreferenciais de aprendizagem

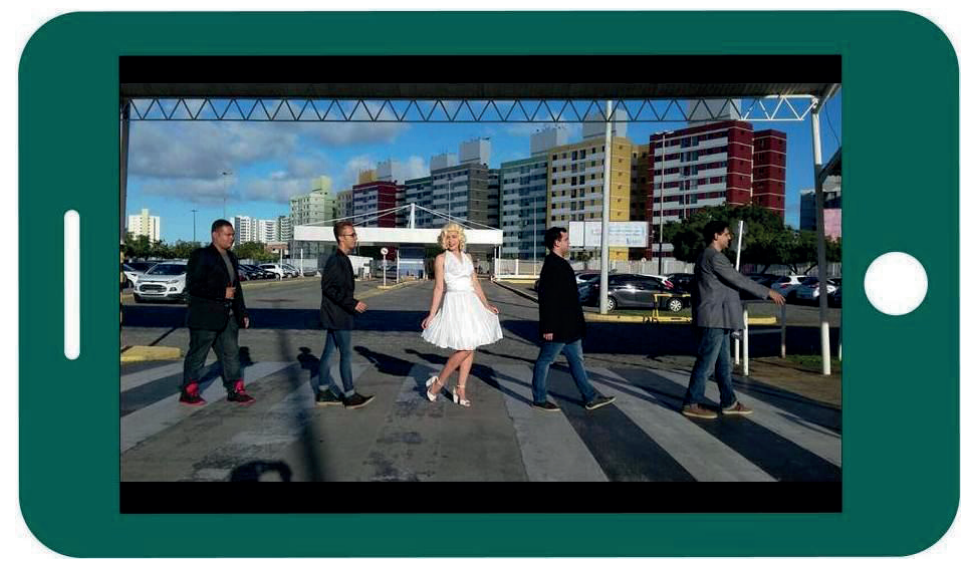

Fonte: Arquivo pessoal de André Alves, 2018. 
Os textos produzidos e postados pelos alunos nos Blogs Temáticos estabeleciam conexões com o conteúdo. E, assim, as discussões das apresentações em sala de aula ocorriam mais timidamente e, para nossa surpresa, o debate sempre tomava proporções mais significativas por meio do aplicativo WhatsApp. Em vista disso, verificamos um contexto mais participativo, fomentando a mediação pedagógica e os fluxos interacionais entre pares - mesclando o ensino presencial com o virtual, dentro-fora da sala de aula e em rede-grupo-movimento. De tal modo, concordamos com Bacich e colaboradores (2015, p. 42), quando estes afirmam que:

O modelo híbrido, misturado, com foco em valores, competências amplas, projeto de vida, metodologias ativas, personalização e colaboração, com tecnologias digitais. O currículo é mais flexível, com tempos e espaços integrados, combinados, presenciais e virtuais, nos quais nos reunimos de várias formas, em grupos e momentos diferentes, de acordo com a necessidade, com muita flexibilidade, sem os horários rígidos e o planejamento engessado.

Logo, este modelo híbrido une o modo presencial com o online de ensinar e aprender, para criar uma combinação do "melhor dos dois mundos" que o Ensino Superior contemporâneo pode proporcionar a seus alunos, com ênfase na aprendizagem significativa.

Outra possibilidade com o aplicativo foi o seu uso como recurso de produção de textos colaborativos, das práticas de leitura e de expressão escrita. Dessa maneira, os alunos eram sujeitos a temas atuais e expressavam sua opinião sobre, como forma de debater, enriquecer e também exercitar os conteúdos vistos em sala de aula. As atividades de produção de textos colaborativos, propostas no grupo da turma, ocorriam em diversos momentos, deixando os alunos livres para "alimentar" os fluxos interacionais da "WhatsAula" com seus textos, opiniões e, também, referências sobre o assunto em pauta. Porém, com um prazo estabelecido para o fim das postagens - além do nosso acompanhamento e mediação e, até mesmo, entre os próprios universitários, "[...] sendo que a base da aprendizagem colaborativa está na interação e troca entre os alunos, com 
o objetivo de melhorar a competência dos mesmos para os trabalhos colaborativos em grupo" (LEITE, et al., 2016, online).

Esta atividade gerou fluxos interacionais intensos, mediante a contribuição argumentativa de todos os interagentes, sem exceção. Por consequência, elegemos, junto com toda a turma, por critério de melhor desempenho, junto às apresentações do Blog Temático, o Grupo Cultura Pop, para filtrar todas as opiniões compartilhadas na "WhatsAula" e condensá-las em um único texto. Com este desafio lançado, os membros do Cultura Pop ganharam uma semana de dispensa das apresentações do Blog.

Figura 6 - Screenshot dos fluxos interacionais da "WhatsAula"

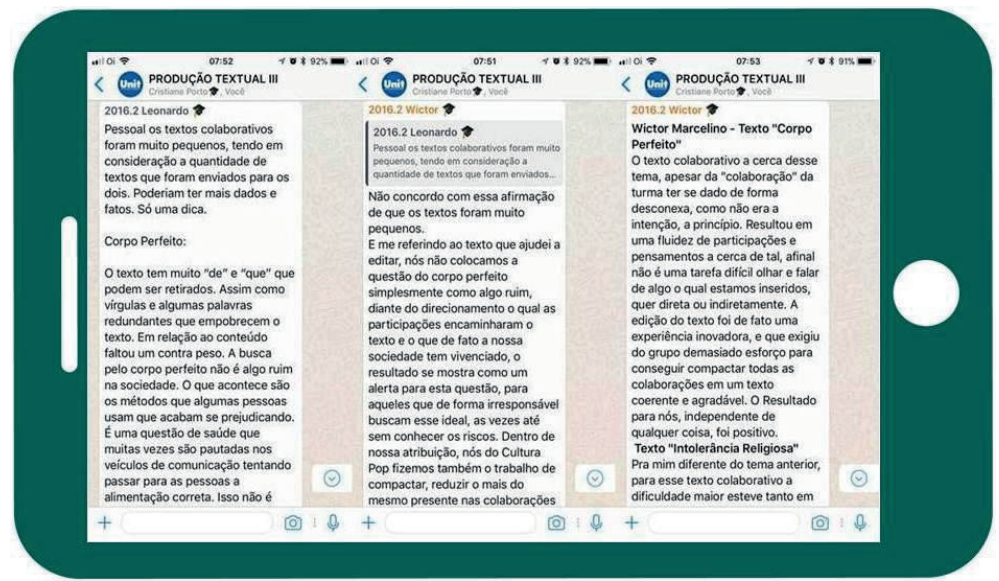

Fonte: Screenshot dos fluxos interacionais da "WhatsAula", André Alves, 2018.

Logo, devido à complexidade da incumbência, selecionamos somente duas produções textuais colaborativas e algumas capturas de tela (Figura 6) acerca do posicionamento crítico de alguns alunos que consideramos relevantes. Tais como: o aluno @Leonardo aponta inúmeras falhas quanto ao texto final e o aluno @Wictor é bem taxativo ao discordar e relatar a satisfação e dificuldades encontradas durante o processo de compilação e produção textual colaborativa. 
Ainda nessa perspectiva, a aluna @AnnaMoser emite um parecer favorável acerca desta experiência de ensinar e aprender juntos e sinaliza que "Intolerância Religiosa" foi o tema da Redação do Exame Nacional do Ensino Médio (ENEM)². Um ponto curioso foi o fato da aluna @AnaPaula compartilhar sua avaliação sobre esta experiência por meio de arquivos em PDF. Assim como a aluna @AnnaMoser, o aluno @Evaldo utiliza o termo "brincadeira", por se tratar de uma prática pedagógica dinâmica, mas ambos reconhecem o quanto esta ação potencializa a aprendizagem. Por outro lado, o aluno @Saullo expõe os erros detectados junto ao produto final e não perde a oportunidade de elogiar (Figura 7).

Figura 7 - Screenshot dos fluxos interacionais da "WhatsAula"

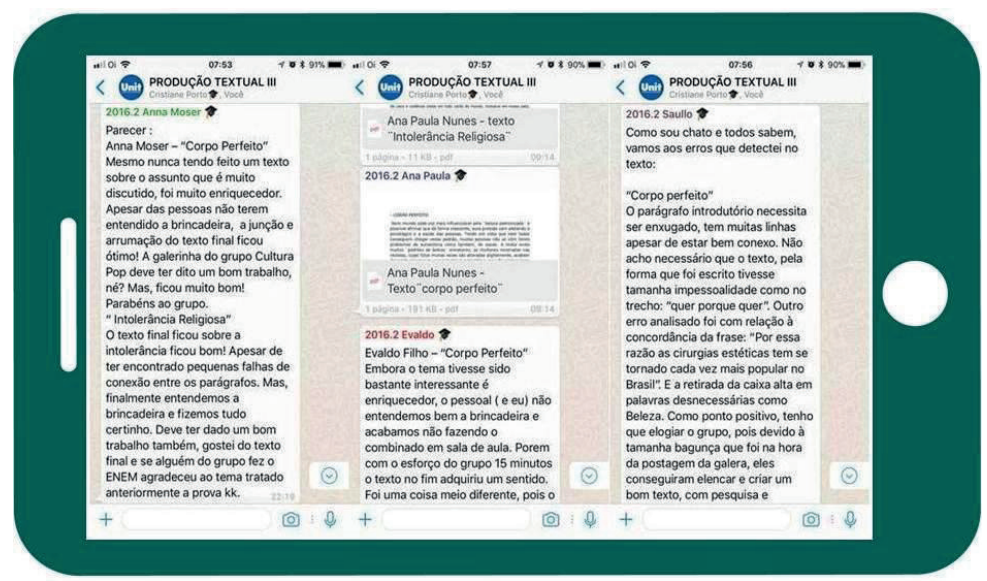

Fonte: Screenshot dos fluxos interacionais da "WhatsAula", André Alves, 2018.

Sabemos que a aprendizagem colaborativa não está ancorada exclusivamente nos artefatos tecnológicos, mas estes têm potencializado oportunidades para que se criem espaços colaborativos nos processos de ensino e de aprendizagem. Espaço este onde professores e alunos colaboram mutuamente em rede-grupo-movimento para a construção do conhecimento. Em

2 O tema da redação do Enem 2016 foi "Caminhos para combater a intolerância religiosa no Brasil”. 
razão disso, utilizamos o WhatsApp como um recurso para a aprendizagem colaborativa que, com seus múltiplos usos e apropriações no ciberespaço pode contribuir para a realização de diversas atividades grupais.

Durante as atividades, os componentes do processo interativo no ciberespaço, chamados aqui de "interagentes" (PRIMO, 2007), se apropriaram dos recursos disponibilizados pelo aplicativo, como mensagens de texto, fotos, imagens, vídeos e áudios para postar seus questionamentos e contribuições sobre as produções dos seus colegas ou intervenções dos professores.

Como forma de colaborar para a aprendizagem, a cada semana, selecionamos o grupo que se destacasse como melhor apresentação do Blog Temático. Este ficava responsável por supervisionar a atividade no aplicativo, reunir todas as informações publicadas e unificar em um texto as diversas colaborações que, posteriormente, seriam apresentadas na aula como produto final. Desta maneira, os alunos desenvolviam as habilidades que o gênero argumentativo exige, isso porque, a dificuldade de argumentação é um problema comum entre boa parte destes, e aprendiam de maneira colaborativa - o que tornava o ambiente educativo mais atrativo.

Tal procedimento da junção da tecnologia e ensino torna o aluno mais autônomo e, por conseguinte, responsável pela construção do próprio conhecimento, de uma maneira mais autoral e colaborativa. É importante salientarmos que, as ações propostas são parte do bloco de "Medida de Eficiência (ME)"3, que compreende o desenvolvimento de atividades práticas e teóricas (apresentação de trabalhos acadêmicos, produção de resenhas de livros, seminários etc.), individuais ou em grupo, com enfoque na autonomia do aluno e relacionadas à atuação profissional futura. Ações estas, referentes às produções de textos argumentativos opinativos, apresentações dos Blogs Temáticos e das Resenhas de Livros e construção do Diário

${ }^{3}$ De acordo com o Regulamento Acadêmico de Graduação da Unit, a Medida de Eficiência corresponde às Atividades Práticas Supervisionadas (APS), desenvolvidas por meio de exames práticos ou trabalhos realizados individualmente ou em grupo, que confiram sentido aos saberes universitários e proporcionem o desenvolvimento do aluno. Sua aferição possui como princípio o acompanhamento contínuo do estudante nas atividades previstas no plano de ensino do componente curricular, para cada unidade. 
de Bordo. Bacich e demais autores (2015, p. 114) discorrem sobre autonomia, afirmando que "o mais importante dessa modalidade de ensino híbrido é possibilitar ao estudante autonomia no aprendizado, pois ele conduz o ritmo e a busca de informações que precisa para aprender".

Esta dinâmica repetiu-se no decorrer das Unidades I e II, percorrendo todo o Plano Individual de Trabalho (PIT) do Professor. Contemplamos um arsenal de aparatos tecnológicos, não isolados, mas combinados, que possibilitaram o acesso, disseminação e construção colaborativa do conhecimento junto aos pares nos mais diversos "ambientes de aprendizagem" - sejam presenciais ou virtuais.

Por fim, tudo o que estava previsto no PIT foi cumprido. As avaliações desenvolvidas em cada unidade programática foram compostas por: Prova Contextualizada e demais trabalhos que compuseram uma avaliação contínua. Esta composição ocorreu de maneira processual, por meio da participação ativa, produção textual, qualidade dos trabalhos apresentados, Prova Contextualizada e frequência ao longo do semestre. Por outro lado, os fluxos interacionais da "WhatsAula" não eram considerados termômetro avaliativo, ou seja, não valiam nota. E, como produto final de cada unidade, os alunos tinham que desenvolver um "Diário de Bordo" acerca de suas impressões, relatos e reflexões sobre as vivências práticas do componente curricular PT-III.

\section{Considerações finais}

Toda mediação entre diversos actantes, atores, agentes, sujeitos, em ambientes e espaços educativos formais ou informais, nos faz lançar mão de uma discussão sobre cultura. Com isso, evidencia que nossa relação com o mundo passa sempre por um mediador artificial (linguagens, artefatos, instituições etc.) e nossas práticas culturais e sociais também. Deste modo, a nossa mediação está diretamente relacionada à dispositivos e depende do modo pelo qual, o processamento, o consumo a produção infocomunicacional, ou não, se dá entre os actantes, intermediários e mediadores (PORTO; OLIVEIRA, 2016). 
Neste trabalho estas práticas de mediações e associações foram evidenciadas pela formação da rede sociotécnica, composta pelos alunos na rede, articulada pela experiência de app-learning com o WhatsApp, na prática educativa do componente curricular Produção Textual III. Quando adotamos a abordagem proposta pela TAR, foi possível evidenciar que o WhatsApp desempenhou claramente um papel ativo na trama, consolidando-se como um misto de sujeito e objeto ao emprestar novas propriedades comunicativas por meio de seus algoritmos tecnológicos a outros componentes da rede. Assim, é preciso considerar a proliferação dos híbridos, agenciamento de entidades em diversas situações, especialmente em espaços educativos.

Logo, foi possível evidenciar que, em contextos de App-Learning - aprendizagem por meio de aplicativos - o fazer docente precisa estar sintonizado aos alunos hiperconectados-multitelas e associados especialmente à performance dos seus dispositivos, que não são apenas objetos, mas produzem causa na rede de interagentes. Isso só foi possível neste contexto aqui discutido com a tática de recombinar e se associar a aparatos tecnológicos, adotar estratégias pedagógicas híbridas-ubíquas e mediar com o suporte do aplicativo WhatsApp, que se consolidou como um dos principais actantes da rede, como conceitua a TAR.

Com a experiência bricolada que denominamos de "WhatsAula", foi possível concluir que o WhatsApp, quando utilizado com intencionalidade pedagógica, é um importante aplicativo de suporte para potencializar os processos de ensino e de aprendizagem. Isso, por se constituir como um espaço-tempo multirreferencial para a construção colaborativa de saberes, além de exercer uma influência expressiva no engajamento dos alunos nos seus estudos e ampliar as discussões e o espaço da sala de aula.

Para Ardoino (1998), o surgimento da multirreferencialidade está ligado ao reconhecimento da complexidade e da heterogeneidade inerentes às práticas educativas. Isso, sempre na perspectiva de uma pluralidade de olhares e linguagens, reconhecidas como necessárias à compreensão do fenômeno complexo que é a Educação. Percebemos que a experiência em tela demanda a compreensão multirreferencial dos fenômenos sociais no âmbito educacional, em tempos de Cibercultura — em 
que "a aprendizagem não se dá entre quatro paredes, ela está além dos muros da escola/universidade, numa relação híbrida com todos os espaçostempos que nos cercam" (ROCHA, 2012, p. 58).

Com a "WhatsAula", observamos que a oralidade e escrita evoluiu consideravelmente, pois os alunos passaram a se posicionar mais e a escrever mais, em função da dinâmica estabelecida junto ao componente curricular PT-III. E o escrever não se limitou apenas a inserir palavras e textos, mas a posicionar-se por meio do hipertexto. Por intermédio da "WhatsAula" os alunos realizaram atividades de pesquisa, como estratégia de aprendizagem para complementar e elevar as produções textuais que eram postadas nos Blogs Temáticos e, também, para promover os fluxos interacionais - possibilitando outros tipos de aprendizagem extracurricular.

Além disso, verificamos que a possibilidade de registro-armazenamento dos fluxos interacionais da "WhatsAula", oportuniza aos alunos faltosos o acompanhamento-participação e o acesso ao que foi discutido na aula física, ainda que não em sua totalidade; a "qualquer hora" e em "qualquer lugar", devido a capacidade espaço-temporal do app-learning. Com a experiência da "WhatsAula", a nossa mediação docente esteve centrada no protagonismo do aluno e na problematização e estímulo da construção colaborativa de saberes associadas aos dispositivos articulados à rede sociotécnica estabelecida; além do auxílio nas atividades grupais e geração de feedbacks no transcorrer dos fluxos interacionais, sem a copresença física dos interagentes.

\section{Referências}

ARDOINO, J. Abordagem multirreferencial (plural) das situações educativas e formativas. In: BARBOSA, J. G. (Coord.). Multirreferencialidade nas ciências e na educação. São Carlos: EdUFSCar, 1998.

BACICH, L.; TANZI NETO, A.; TREVISANI, F. de M. (Org.). Ensino Híbrido: personalização e tecnologia na educação. Porto Alegre: Penso, 2015.

LATOUR, B. Ciência em ação. São Paulo: Unesp, 1999. 
LEITE, C. L. K.; et al. A aprendizagem colaborativa no ensino virtual. Disponível em: <http://www.pucpr.br/eventos/educere/educere2005/anaisEvento/documentos/ com/TCCI167.pdf $>$. Acesso em: 20 maio 2017.

LEMOS, A. A Comunicação das coisas: Teoria ator-rede e cibercultura. São Paulo: Annablume, 2013.

PORTO, C.; OLIVEIRA, K. E. de J. Educação e Teoria Ator-rede: fluxos heterógenos e conexões híbridas. Editus: Ilhéus, 2016.

PRIMO, A. O aspecto relacional das interações na Web 2.0. E-Compós, Brasília, v. 9, p. 1-21, 2007.

ROCHA, A. A. W. N. da. Educação e Cibercultura: narrativas de mobilidade ubíqua. 210f. 2012. Dissertação (Mestrado em Educação) — Faculdade de Educação, Universidade do Estado do Rio de Janeiro, Rio de Janeiro, 2012.

SANTAELLA, L. Comunicação ubíqua: repercussões na cultura e na educação. São Paulo: Paulus, 2013.

SANTOS, E. Pesquisa-formação na Cibercultura. Portugal: Whitebooks, 2014.

VIEIRA, S. L.; HALU, R. C. Utilização de blogs educativosno ensino/aprendizagem de línguainglesa: uma experiência no Colégio Estadual Santa Gemma Galgani, 2014. Disponível em: <http:// www.diaadiaeducacao.pr.gov.br/portals/pde/arquivos/348-4.pdf>. Acesso em:18jun. 2017.

Recebido: 28/01/2018

Received: 01/27/2018

Recibido: 28/01/2018

Aprovado: 25/02/2018 Approved: 02/25/2018 Aprobado: 25/02/2018 